\title{
A CRITICAL REFLEXIVE MODEL: WORKING WITH LIFE STORIES IN HEALTH PROMOTION EDUCATION
}

\section{Norton*}

e-mail: tInorton@iafrica.com

\author{
Y. Sliep* \\ e-mail: sliepy@ukzn.ac.za \\ *School of Psychology \\ University of KwaZulu-Natal \\ Durban, South Africa
}

\section{ABSTRACT}

In this article a critical reflexive model is described and applied to life stories of tertiary education students doing a masters in health promotion. At the heart of the process is the dialogical space where relational reflexivity is facilitated and around which the narrative story is developed. Examples from tertiary education are given to illustrate how working reflexively with life stories increases critical thinking and a sense of identity, belonging and agency. The approach is holistic in that it connects new knowledge to lived experience. It is based on a social constructionist worldview that uses a narrative lens which recognises that our knowledge is continuously constructed in context and in interaction with others. One way to understand ourselves and others is to understand our own and each other's stories. The model which facilitates this process involves four iterative loops: deconstructing power in the collective; mapping values and identity; negotiating agency; and rendering accountable performance.

Keywords: life stories, critical reflexivity, narrative, dialogical space, identity, belonging, agency

\section{INTRODUCTION}

This article explores the value of working from a narrative reflexive perspective in health promotion education and more widely to bridge the gaps in education between theory and practice, academics and community involvement. A critical reflexivity model is interrogated as a methodology and tool for connecting students to their lived experience and their social and historical context. This is done through using life stories to connect personal discourses to dominant societal discourses to better understand the power at play in our society. Telling and deconstructing our stories leads us to a better understanding of how we position ourselves in society in terms of our values and identity. It also facilitates a process of reflexivity that enables us to then question our positioning within our contexts leading to agency and action. Witnessing 
the stories of others leads us to a better understanding of the relational ties that bind us together. In this way collective agency and social performativity are enabled.

We look first at the concept of reflexivity and how this is viewed in terms of a framework developed over time to facilitate reflexive skills in education and then link this to a narrative approach. Using life stories in education paves the way for students to develop deeper insights into their own learning processes and goals, and to play a more active role in shaping their own contexts in which they live, study and ultimately work (Sliep 2010). The overall approach is then explored through the voices of students who have been involved in the Personal is the Professional module which is part of the Health Promotion and Communication Master's at the University of KwaZulu-Natal (UKZN). This module was developed by the second author specifically to create a learning space for students to collectively construct and deconstruct their social and educational worlds through the sharing of life stories.

\section{CRITICAL REFLEXIVITY}

The terms "reflective" and "reflexive" are used in various ways throughout the literature and across various disciplines (and sometimes interchangeably) (Fook, White and Gardner 2006; Gilbert and Sliep 2009). However, this article intends to define the terms specifically for the purpose of providing a working definition for use as a basis of a conceptual framework aimed at developing critical reflexivity. Reflectivity is generally viewed as a process in terms of which a researcher pays attention to the self as a constructed object, taking into account their social context and their effect on their research (Gilbert and Sliep 2009). Reflexivity, however, goes further than reflectivity in the sense that it is both an approach to research and a way in which one can learn from practice - an educational tool that aids in critical knowledge production (Fook, White and Gardner 2006, 18). While reflection on its own aids recognition and awareness, this is not viewed as sufficient. We also need to take into account our embodied transactions, do our beliefs match our actions and our actions our beliefs? (Door 2014). A reflective researcher may become aware of their positioning but still act through that same lens or specific logic. The reflexive practitioner is more able to move beyond their own philosophical positioning and becomes open to multiple standpoints (Gergen 1999; Gilbert and Sliep 2009). Door (2014) argues that our actions and responses to others should be in alignment with our advocated ethical stance. Reflexivity then extends reflection and "includes the embodied self and its response to the other selves with whom that self interacts, and ... incorporates thoughtful action in the moment” (Door 2014, 91).

Of significance to this article is a definition of reflexivity as an ongoing critical appraisal of self and others in action; understanding how our actions are formed by our context and our 
relationships to others (Gilbert and Sliep 2009). In relation to self-reflexivity this involves understanding how we position ourselves and how our positioning is affected by dominant discourses. In acknowledging reflexivity as a relational process, it is viewed as occurring in context, as dynamic and iterative, influenced by our past and present social interaction with others and how we position ourselves in relationships (Gilbert and Sliep 2009). Understanding how we are influenced by the discourses in our lives and becoming aware of and acknowledging the norms and values we and others around us ascribe to means that we can better position ourselves to start living our preferred story. Fook, White and Gardner $(2006,18)$ argue that "a reflexive ability is central to critical reflection, in that an awareness of the influence of self and subjectivity is vital to an appreciation of how we construct and participate in constructing our world and our knowledge about the world”. Reflexivity then can be viewed as an interactive and empowering process that facilitates an understanding of how we can better live together, communally, in our world.

Individual, collective and social action all involve a complex network of interlinking relationships that need to be understood in context and in terms of space and time. We are who we are because of our social interactions over time with others in our past and present. Understanding who we are and how we view our world and are shaped by the world around us is part of a reflexive process. Such a process demands an examination of our own and other's historical, political and cultural assumptions and intentions so that we may better understand both ourselves and each other (Gilbert and Sliep 2009; Sliep and Norton 2016). Gergen (1999) sees this as the capacity to look beyond our own "obvious" realities so that we are able to listen to alternative representations held by others.

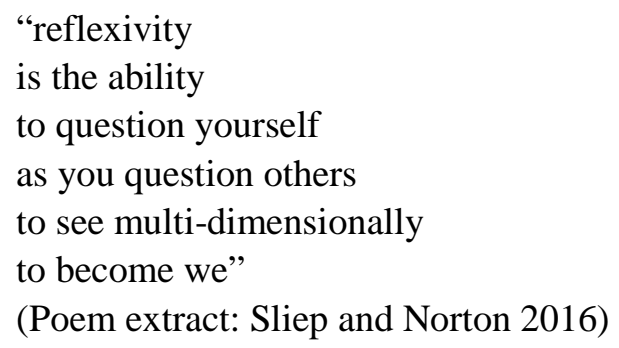

\section{THE PROCESS OF REFLEXIVITY: DEVELOPMENT OF A CONCEPTUAL MODEL}

The process of reflexivity as described above was initially conceptualised by Sliep and Gilbert (2006) and has been refined over time resulting in the development of a critical reflexive model (Gilbert and Sliep 2009; Sliep 2016; Sliep and Norton 2016). The model has evolved to take into account multi-disciplinary and multi-level applications where context and relationship are of paramount importance. It is based on social constructionist principles in terms of which 
"reality" as we know it is constructed or brought into being through social action (Holstein and Gubrium 2011, 341). In a relational sense, this means that we create our understandings with others around us, through relationships, dialogue and interactions (Cunliffe 2008). As stated above, reflexivity is viewed as a process that is both dynamic and iterative. It is an ongoing practice of testing our assumptions and intentions that takes into account how our actions are influenced by our context and how our context is, in turn, influenced by our actions. When we understand that we create meaning and a sense of self in relation to others in our contexts, reflexivity becomes a morally responsible activity as we begin to test our assumptions and intentions so that we can interact with others more ethically (Cunliffe 2008). Gergen (1996) views us as performing in relationship, which enables us to engage more meaningfully with how and why we act in certain ways and how we position ourselves within society. In terms of the model our meaning making involves moving back and forth through four loops as part of a process of generating critical reflexivity and social and relational understanding as illustrated in Figure 1.

\section{Critical Reflexivity}

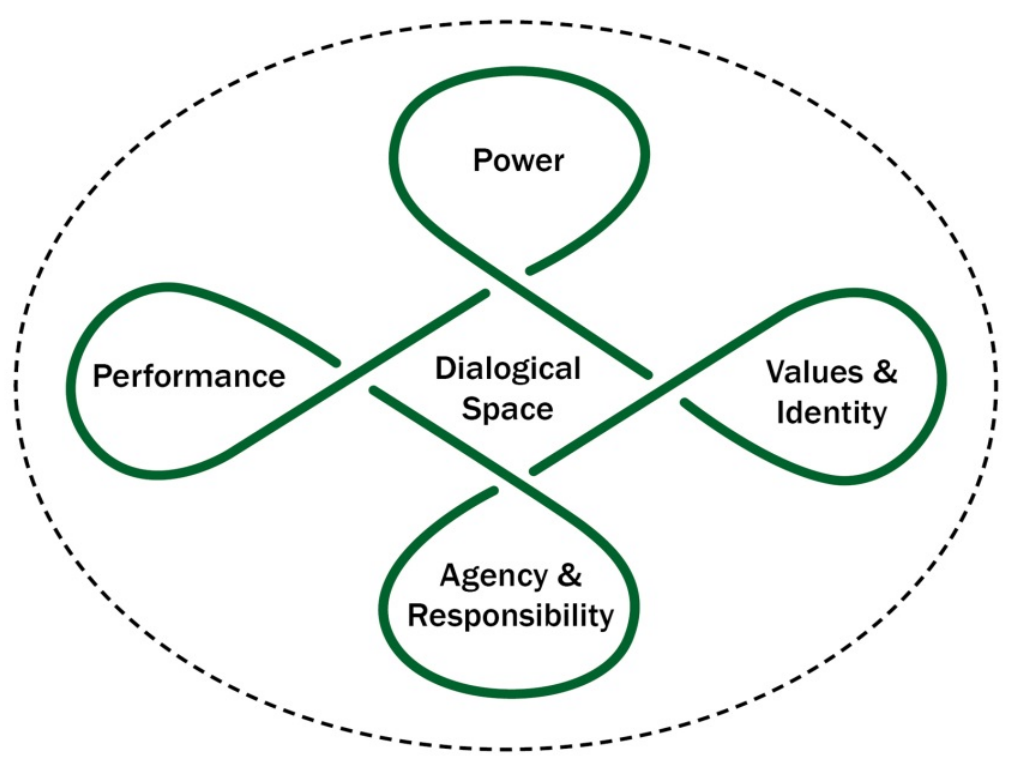

Figure 1: Critical Reflexivity Framework (Gilbert and Sliep 2009 ; Sliep 2016; Sliep and Norton 2016)

Moving through the loops involves deconstructing discourses on a societal level as well as exploring the mechanisms of power in your personal life; an awareness of your values and identity leading to an interrogation of responsibility and agency which, in turn, engenders social 
performativity. At the centre of the loops and the heart of the process is a dialogical space that facilitates a process of dialogue that enables one to understand that there are many truths and that what one person perceives as reality may not be so for another (Bohm 1996). A safe space is facilitated to support such understandings and the dialogue that is encouraged is linked to a socially transformative agenda involving a commitment to engage with and learn from each other (Rule 2004).

The critical reflexive model has been usefully applied in various contexts including higher education (Sliep and Kotze 2007); qualitative research (Naidu and Sliep 2011); school projects (Sliep and Norton 2016); and a variety of community projects (Sliep 2003; Sliep and Gilbert 2006). The model can be used in different circumstances to increase self and other awareness, improve social understanding and contextual perception through a better understanding of the power dynamics at play, more attentiveness to values and identity, linking agency to moral responsibility, and social rather than more limited individual transformative performance. It can be used as a research and practice approach; as a tool for analysing social issues and improving social cohesion; and for engendering reflexive skills in individuals or groups. Additionally, by applying a narrative approach to the framework a clear link is made to the importance of context, culture and community.

\section{SHARING STORIES: USING NARRATIVE TO FACILITATE REFLEXIVITY}

How we interpret our lives is important. Narratives help us to find meaning in our lives and as part of a relational process help us to move towards not only a preferred story about the self but towards a collectively coherent story. A narrative approach based on constructionist principles helps us understand our cultural heritage and our context, how they shape us and how we understand ourselves and others. Recognising that knowledge is constructed communally opens a space for understanding our lives and those of others through examining our lived experiences and connecting these to the complexities of our society. The apparent contradictions and divisions in narrative inquiry between the idea of a singular subject learning from experience through their stories, and those stories as socially constructed and open to multiple interpretations has been highlighted in the narrative literature and are not discounted (Tamboukou, Andrews and Squires 2013). Many researchers, however, resolve to work with the inconsistencies and bring them together in their quest to treat narratives as emancipatory or “modes of resistance” to prevailing power structures (Tamboukou, Andrews and Squires 2013). This is important in applying a narrative approach to reflexivity which involves using stories to help people change their social situations (Tamboukou, Andrews and Squires 2013; Sliep, Weingarten and Gilbert 2004). Stories in this sense, as in socio-narratology, are viewed as 
"actors" and the focus is in what stories "do", rather than using stories to attempt to understand the mind of the single storyteller (Frank 2010, 13). We view the term "experience" here as not something that is uncontested or a taken for granted "truth” reflecting an individual's past but rather as a political "event” and something that in Scott's (1992, 38) words is "that which we want to explain". It is not the particular content of the stories or the expressed experience that is important, but that the narrative reflexive process facilitates an ability to question that content, experience, or event and to look at it in different ways. Telling stories and witnessing those of others around us enables us to look more widely, to see and experience multiple viewpoints. Deconstructing our stories helps us to understand the lens through which we view the world and opens us to a better understanding of how other viewpoints are constructed through different story lines. We are then in a better position to understand and value others.

The characteristics and benefits of a life-history/narrative investigation have been summed up by Suarez-Ortega (2013) and include: prioritising participants' subjective consciousness (meaning is constructed so can be re-authored); a focus on culture and context highlights the collective nature of story-telling; and both micro aspects which are directly a part of the storytellers' lives, and macro aspects involving the larger cultural, social, political and economic context come into play. These open the way for the development of reflexive knowledge through a holistic approach, linking the individual to the community and to larger societal and historical aspects. We need to listen to each other's stories, to understand that we operate from different realities but that it is still possible to shape new stories collectively. Creating shared meaning together can lead to positive social outcomes. This does not happen on its own but requires both self and relational reflexivity and nuanced social understanding, as part of the storied process.

When the critical reflexive model is used in conjunction with a narrative methodology the process of reflexivity is enhanced through the telling and witnessing of life stories. Telling and deconstructing your story enables you to recognise and break down the influence of dominant discourses in your life. Examining your values and identity through your own story allows you to then position yourself in your story which, in turn, moves you to a place of agency and responsibility. In the fourth loop, you move towards living your preferred story. When this takes place in the presence of others, it is in witnessing their stories that you are better able to understand their realities and move together towards a preferred collective story in which everyone is important; rather than being limited by individualistic outcomes. This process is illustrated in Figure 2. 


\section{Narrative paradigm in reflexivity framework}

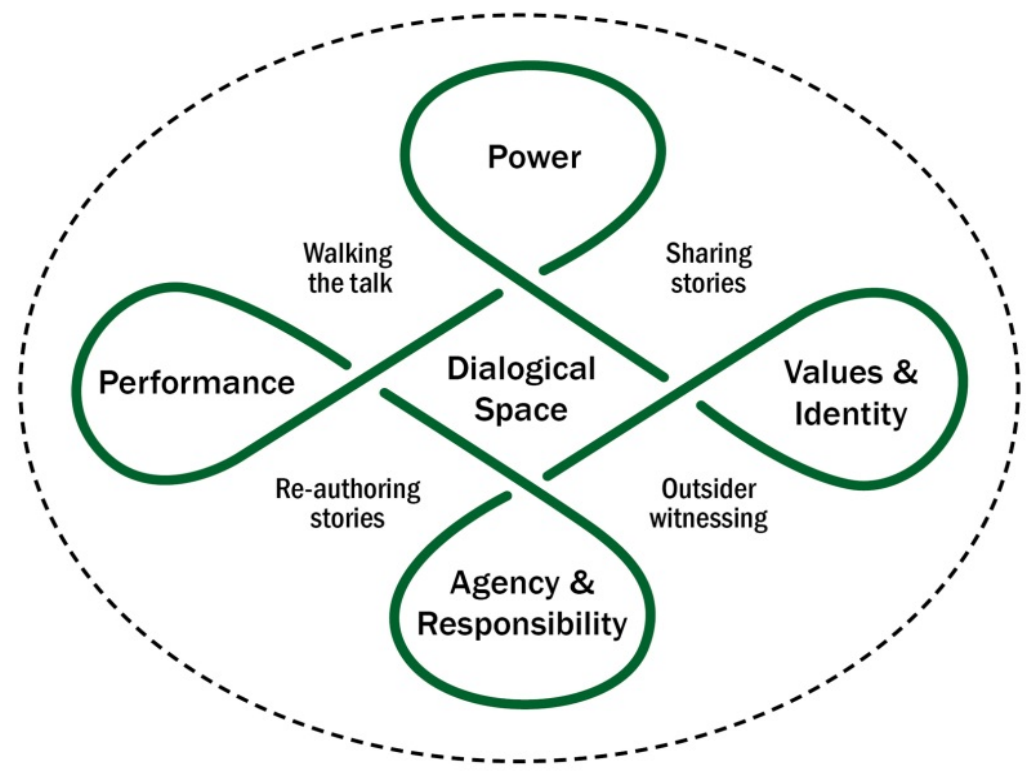

Figure 2: Narrative paradigm in reflexivity framework (Sliep 2016; Sliep and Norton 2016)

A narrative life story approach that is reflexive in nature takes place in an interpretive framework and is grounded in principles of Critical Communicative Methodology (CCM) (Suarez-Ortega 2013). CCM stems from a belief that all people have the ability to analyse their own reality and the right to offer arguments and to do so using their own language (SuarezOrtega 2013). When stories are explored within a reflexive framework, participants are invited, through examining their own story, to recognise the power at play within dominant discourses that can then be challenged. This opens the way for the structuring of a new story and the development of both agency and a critical consciousness. Although there are challenges to the legitimacy of life history methodologies, they have become increasingly popular (Dhunpath 2000). Dhunpath (2000, 544-545) suggests that such an approach is "probably the only authentic means of understanding how motives and practices reflect the intimate intersection of institutional and individual experience in the postmodern world" and coins the term "narradigm" to support the reality that our lives and the way we experience our world are narrative in quality.

\section{NARRATIVE REFLEXIVITY IN EDUCATION AND HEALTH PROMOTION}

Prior research indicates that transformation in education is considered as more than just adding to learners' skills and knowledge base. It is rather viewed as an "ongoing change in the way 
educators and students approach the acquisition of knowledge and skills and relate them to a broader context” (Waghid 2002, 459). Such transformative teaching and learning is considered to connect "new knowledge with lived experience, resulting in an on-going construction and reconstruction of personal, professional and contextual narratives” (Sliep 2010, 109). With a recognition that knowledge is co-constructed (Gergen 2009), the path is opened for students to participate more actively in their own learning. Facilitating reflexive skills and critical thinking through sharing and deconstructing life stories means that there is a privileging of context and community rather than the more individualistic approaches of Western society; more attention is paid to the rich contributions of indigenous knowledge systems through personal storytelling; and the voices of students become part of the co-construction of knowledge. Stories are also viewed more practically in education as ideal vehicles for students to make learning meaningful, to retain concepts, to make better sense out of their observations, and to develop multiple perspectives rather than being stuck in the belief that their own views are the only and correct ones (Morgan and Dennehy 2004).

In relation to teaching and learning, “[r]aising critical consciousness involves a significant learning experience with a real world context” (Mangadu 2014, 11). This means that learning experiences only reach significance when they go beyond subject content and allow for the application of knowledge in real world contexts. Critical thinking and consciousness, through reflexive learning are therefore the cornerstones for becoming independent and active learners (Mangadu 2014). Gergen (2009) stresses the importance of viewing education not as a process of individual success or failure but believes its overall aim should be to increase individual and group potentials for participating in both local and global relational processes. Effective education should then consider the productive participation of individuals in family, community and other social and political structures, and thereby foster "processes that indefinitely extend the potentials of relationship” (Gergen 2009, 243). This can only be achieved through participatory forms of inclusion, taking into account the lived-in contexts of learners in order to "bring multiple worlds into coordination, and to replace divisive hierarchies with mutual appreciation” (Gergen 2009, 255). As such, all education but particularly education that is aimed at developing professionals who will serve society such as health promotion professionals, requires that we favour a deeper understanding of context. This is possible through dialogical and reflexive practice.

Reflexivity is made possible through working with individual and group personal experiences, life stories and through dialogue. In an educational setting, it is in the telling of personal life stories that educators and learners begin to work with the "lived experiences" of learners, contextualising them and enabling an exploration of the complexities of society. In 
this way personal discourses of learners are linked to their professional lives. Life stories connect new knowledge to personal context and through this students' understandings of the learning process are improved and can then serve as a guide for future learning. The critical reflexive model enables learners to critically reflect on meaning in both their own lives and the lives of others, and thus provides a "map to show where agency is played out” as learning and application are integrated (Sliep 2010, 115).

More generally, stories are viewed as tools for living that enables one to reflect and therefore to better understand, negotiate and create; leading to potential transformation on both a personal and social level (Suarez-Ortega 2013). In terms of an ecological view of agency, lifenarratives are believed to be an important vehicle for the realisation of agency in one's life as something that is not merely possessed but achieved when individuals actively engage in understanding their actions within their own contexts (Biesta and Tedder 2007). In the construction of meaning within a life context there is an acknowledgement of voice, and the right to be heard, which is especially important for those who have been or are socially excluded (Suarez-Ortega 2013).

Table 1: Life stories and reflexivity: Adapted from Sliep (2010)

LIFE STORIESI Narrative Biographical Method

- $\quad$ Telling your life history (as storyteller)

- Telling your story to others (being witnessed)

- $\quad$ Telling your story amidst others (as witness)

- Deconstructing and re-telling

- Discovering critical learning incidences

- Exploring current life challenges and aspirations

- $\quad$ Shaping preferred future outcomes

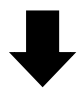

Developing contextual narratives
Self + Relational - reflexivity

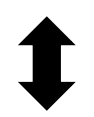

- Critical consciousness

- Contextual savvy

- Increased agency

- Social performativity

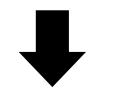

Connecting Lived Experience + New Knowledge

Additionally, the impact of sharing life stories following a reflexive process means that:

- Narrators get a stronger sense of who they are by looking more closely at their life's journey - their history, discoveries and current life circumstances.

- A greater sense of validation is created - their stories do matter, where they come from and what they have lived through all matter and make them who they are today.

- Narrators are better able to value the knowledge that they have developed over time through life experience. 
Through sharing and speaking out, the value of your own knowledge and experience is anchored. In narrative theory outsider witnessing leads to your position being affirmed by others. Further, when your voice is heard you are no longer invisible, but "seen" for who you are. In turn you are able to "see" yourself and embrace your culture and who you are, without having to hold onto negative aspects that have challenged you. During this process your identity and sense of belonging is affirmed. Students can start to understand that their voice is important and that their opinions matter, enabling a sense of agency. However, it is important to understand that these forms of affirmation do not always happen and are not automatic, but need to be carefully facilitated. These processes can work well in small groups where stories are shared and only when an atmosphere of trust, respect and being non-judgmental has been built in the dialogical space.

\section{DIALOGUING WITH THEORY AND METHOD: STUDENT EXPERIENCES OF NARRATIVE REFLEXIVITY}

We now explore the model in practice; following a participative approach with a group of eleven Health Promotion masters' students from UKZN who have shared their life stories in the Personal is the Professional module during 2016. This group forms part of a larger research project that explores the benefits and effects of reflexivity and life stories in tertiary education over a fifteen year period. The material offered below is used with the consent of and in reflexive dialogue with the students. It is used illustratively in this article rather than as a body of research data to show their experience of developing reflexivity through sharing and deconstructing their stories focussing on each aspect of the model. Students taking the module are invited to undertake a reflexive exploration of their histories (through life stories), lived experience (critical learning incidents), current life challenges, and aspirations. These are explored through a number of experiential exercises, for example, developing a tree of life, writing your story in the third person, reflecting on other student's questions and on how each loop of the critical reflexive model (power, values and identity, agency, and performance) impacts their understandings and insights. Working in this way involves a critical examination of intersectionality and the positioning of individuals both physically and through discourse, with students being encouraged to move from theory to practice and back from practice to theory.

Using the words of students, we now construct an illustrative overview of their experience of critical reflexivity: 
“Hearing other people's experience made me realise and appreciate how unique everybody is but at the same time how some things or experiences are common across different cultures, origins and people."

\section{Dialogical space}

At the core of reflexivity is the dialogical space, a safe place that is specifically facilitated by the educator to make it possible to tell your story and undertake the reflexive exploration that is asked of the students. It is a facilitated space of trust that encourages dialogical interaction and an examination of students' pictures of reality, to understand, by listening to others, that these pictures are constructed truths and may not hold true for everyone. Although also a physical space, when it is filled with stories told within a trusting environment, it becomes possible to open up to multiple, alternative viewpoints. Such a space requires certain conditions to be in place for the process of reflexivity to "work." A culture of "critical acceptance" is considered essential in the creation of a climate of respect where it is safe to question old viewpoints and to try new ideas (Fook, White and Gardner 2006, 16). People are encouraged to be open, non-judgemental and dialogue is stimulated. Communal dialogue in itself is viewed as having the potential to "create a space for cultural exchange that draws on language and social representations” (Skovdal and Abebe 2012, 80). In such a space teachers and students come together as equals and are valued not in terms of their positions of power (although power inequalities and tensions are not ignored) but rather for their intrinsic relevance and value (Skovdal and Abebe 2012). This student's reflection reveals her experience of the space created:

"I feel so safe and secure and I can safely say I have found a home away from home. I can safely share my experiences and it's so amazing how I managed to speak about some personal stuff that I had never found the space and courage to talk about.”

Using words taken directly from the life story and reflections of one of the students the following poem was created to illustrate the response of the student to being in a safe dialogical space that allows someone to be heard in their "wholeness," to bring all of him and his experiences into the space:

"Finding dialogical space

corridors of gray closed doors

uninviting clinical disarray

functional space, sensible

and academic

I am shy and nervous

sitting upright

and exposed

I will only say what I think 
they want to hear

I used to sit

in back rows uncertain

alien and uninvited

no one knows

where I came from

no one knows

my family, my history

the mountains

where I herded goats

no one knows

of the time

I spent hiding

in the forest

because I couldn't pay

for my school uniform

no one knows

where my strength

comes from

of the mountains

where I prayed

no one knows

no one asked

until today

in this small gray

room with broken

air conditioners

I'm sitting now

bent forward

in a tight-knit group

we build a nest

for an unexpected egg

bought in from home

collect pieces of nature

from the world outside

this never happened before

in this institution

a banking system

now I am touching life

for the first time

since I walked down

these corridors

of gray closed doors

today I was asked

to tell my story

bring in my past

to bring the mountains

and the goats

my father's early death

into this room

I have been asked

to bring myself

into this room 
at the end of the corridor

of closed gray doors

I am invited to speak

and I will tell you

the truth”

\section{Power}

Students are encouraged to critically examine the operations of power in their lives on a personal, structural and political level. They are required to look at their own story within the dominant story and to see who holds power and why, and to attempt to make sense of how current dominant discourses impact how they position themselves. This is more about understanding power than trying to dismantle it; and through understanding, to shift and move their own perspectives around power. Recognising the constraints and in some cases the advantages of personal, social, and political power, students highlight examples from their life stories:

Personal: "It is my personal power in self-belief that has kept me up to this far ... to my postgraduate studies. This has happened despite my poor family background which did not deter my ambitions or goals of furthering my studies.”

Family: "In my culture power resides with one’s parents ... 'you are always a child in the eyes of your parents', this phrase has been used by my parents especially my mother who believes that the parent is always right because of her age and years of experience .... Because of the power she had over me (financial, emotional and social) I could not do anything to stop the abuse.”

Social: "My culture dictates that Indian women have to fulfil multiple roles such as wife, daughter, chef, maid, student, daughter-in-law and mother. These roles take priority over my education ... have to be fulfilled to be considered a good Indian woman. The inability to meet these requirements results in your family name being lowered or losing value and power in society ... my choices are limited by my family, cultural and societal context."

Political: "Because I am a Zimbabwean ... the government sets boundaries on how I can live my life here in South Africa as a foreigner."

Deconstructing the webs of power surrounding the self and community leads to a questioning of identity and values. Who am I within this context? Who are we within this context?

\section{Values and identity}

In telling their stories individual students are invited to examine their own values and identity and where these stem from. Values are not based on or examined in terms of some universal principal but rather in terms of collective negotiation and communal participation. In relation to the group, social thinking is facilitated to work towards recognition of different views and 
interaction between each other that is for the collective benefit. Using an experiential poetry exercise for students to reveal their values amidst their life stories, one student wrote the following poem which she said she "didn't know" she was going to write. Reading the poem aloud to her fellow students was a very moving experience, creating space for her own and others further reflection. The poem reveals a core value relating to forgiveness in the life story of the student and aligns with the role that forgiveness has played in South Africa through the Truth and Reconciliation process which started 20 years ago:

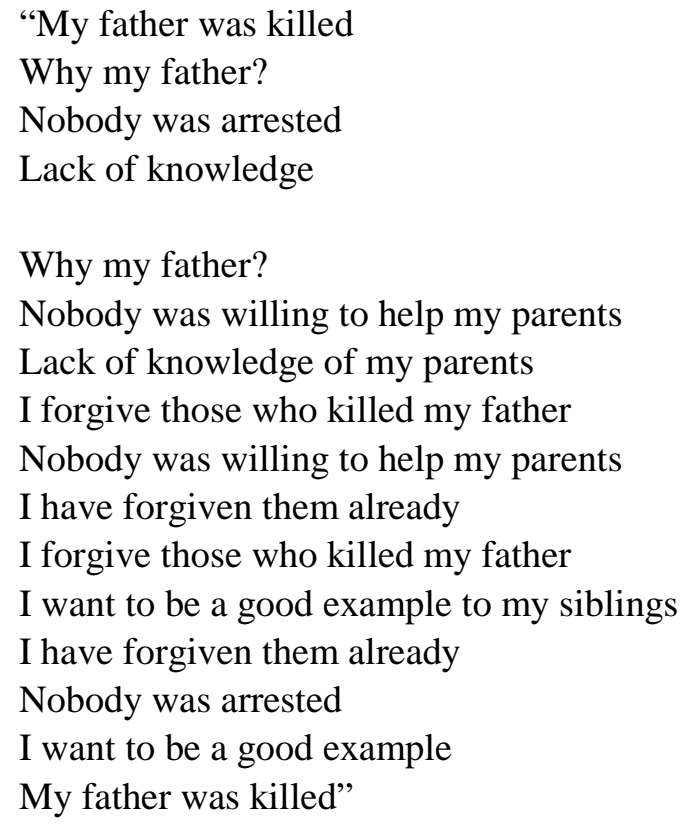

Further examples and close scrutiny of students' values also revealed that there is not always an alignment between individual and cultural values and this can create a discord which requires some negotiation. For example, a female student from Zimbabwe says:

\footnotetext{
"Wearing of trousers is considered to be inappropriate and an insult to the Shona cultural values ... but ....

The way I dress does not define my character ... but ...

I would prefer to align to the cultural values around dressing whenever I visit my rural home as a way of respecting my elders.”
}

These examples show the need for a nuanced understanding of agency, moral responsibility and the need to negotiate your position within a community or societal context.

\section{Agency and responsibility}

Opening a space for students to tell their stories, to be self-reflective and to become more selfaware helps to increase a sense of agency. Bandura (2001) views agency as emergent and people 
as having the ability to make choices and to take action. He stresses the importance of efficacy beliefs, and a sense of control as foundations to personal agency and a major influence on personal development. Storytelling encourages coherence, sense of control and meaning, and in this way stimulates a sense of positive agency. Where this is done within a safe, dialogic space all views are heard, including marginalised voices. Further, different modes of agency are recognised including individual, proxy and collective agency (Bandura 2001), all of which may be encouraged as different forms that may be more supportive depending on the relevant circumstances. A student from Burundi highlights understandings that lead her towards agency:

"There are many intersecting or interlocking dominant discourses that are prevalent in my life that resulted in the oppression and discrimination of myself, my parents and foreign nationals such as age, nationality, class, gender and religion. These intersecting categories have all collectively helped me shape and understand my personal as well as collective agency."

\section{Accountable performance}

Performance requires living the preferred story, putting words into accountable action, or walking the talk (Sliep and Norton 2016). Students need to consider the issues that have arisen and work out how they can be dealt with in alignment to their values, identity, and in terms of moral and collective responsibility. Performativity in relation to inter-relational reflexivity means that people need to examine the way they speak and act in relation to others; to understand and acknowledge how they and others are positioned in terms of dominant discourses; to be transparent about their positioning; and to advance social action that is beneficial to all involved. Performing reflexively therefore requires action that is accountable and informed by the bigger picture, one that takes both context and the overall reflexive process into account. What is required is a "pulling together" of all the loops which results in actions and decisions which are based on:

- $\quad$ an understanding of context and culture;

- $\quad$ an awareness of power - personal, social and political - in respect of all stakeholders;

- consideration of own and others values and identity;

- $\quad$ moral agency for positive performativity; and

- a commitment to dialogue, negotiated positions and actions.

Further, it is important that this moves from a mere academic exercise into external practice. Are your personal values reflected in your professional life? Social and power differences should be made visible, marginalised voices should be heard, oppressive discourses should be challenged and care should be taken with how language is used. It is only in this way that it 
becomes possible to move towards just and equitable practices or positive social performativity.

"I am becoming more accommodating of opposing views, different religions, and cultural practices. Personally I have become more interested in people and believe everyone has a story and has enriching experiences that have shaped them. My way of life or faith is not the only absolute way.

This is what I believe is the concept of 'walking the talk', where I am actively doing something (studying health promotion) to help me in my future goals of becoming an advocate for marginalised women, children and victims of conflict situations.”

The above reflections clearly illustrate why reflexivity is important in health promotion work. As a health promotion professional it is important to listen to others stories without judgement and to see the whole person and their context.

\section{TRANSFORMING PERSPECTIVES: FROM REFLEXIVE STUDENTS TO REFLEXIVE PROFESSIONALS}

What is important in terms of reflexivity and accountable performativity in education is to equip students for their future professional lives with the capability of being reflexive - facilitating the development of a skill that supports critical thinking and critical consciousness. What is required is a shift in perspective, a new way of thinking that is emancipatory and transformative. Critical consciousness has been described as a process involving continual reflection on and examination of our own assumptions, biases, and the way we perceive our worlds (Sakamoto and Pitner 2005). When critical consciousness is "embedded in action” through a reflexive process it signifies a shift or movement, a change in the status quo (Gilbert and Sliep 2009, 473). In this way reflexivity becomes a tool for interrogation, change and transformation. Reflexivity used alongside story telling means that these shifts take place within a particular context, culture and community. These shifts are grounded in lived experience and can take root precisely for this reason. Our culture, history and community are acknowledged as part of our world view. Their role is not diminished but rather scrutinised, enabling the development of a more authentic but critical lens through which to interpret our world, make decisions, and take action.

The reflexive process that begins with the narration of your life story can be viewed as a journey, one that is not always easy. A road not straight, but crooked and rutted. You find yourself going back and forth from the personal to the theoretical and back to the personal, seeking connections and asking questions. The process is both challenging and uncomfortable. At times you become lost and experience a sense of disorientation - you continually question your position, and this is part of the process. It is only once you have gone full circle, reflected on all aspects (power, values and identity, agency and responsibility, and accountable 
performativity) that the dots become visible and you start to join them together. In this way it becomes possible to link your own life experience to theory and begin to understand theory in terms of your own context. Theoretical understanding becomes grounded through this process and only then does it become possible to for you to tie the fragments together and see the bigger picture. A reflexive journey or process is not automatic and although there may be various ways to travel, working with an established methodological framework can aid and quicken the process. It is through this exploration that essential connections are made between: self and other; theory and practice; the personal and the professional. Journeying with others means that not only do individual stories start taking shape, but social identities can be reinforced and recreated.

The reflexive process is beneficial in steering a person forward towards accountable performativity. Once someone has "found" their voice, it is often the case that they feel very proud of where they have come from and having come through the many struggles that they have endured. Instead of seeing these struggles as negatives, on reflection they are able to see their own strengths in having come through their challenges "against all odds". Their own indigenous knowledge and experience becomes a point of reference, something to be valued and built upon. I am who I am because of my past experience with others ....

\footnotetext{
"I had to drop out of school due to my family/parent's financial obstacles ... my brother and I spent the year looking after the home cattle and we used to leave home early in the morning to spend the entire day on the mountains with the cattle ... this became our daily bread ... I started developing a strong relation with God in the mountain as I used to pray a lot whenever I was in the field. This is the strength I still have now which keeps me connected to God.”
}

"I am determined to go for things that I have failed to achieve before because of the experiences I have shared this past week (during the module). I realised that all the challenges I have faced, someone has experienced them and passed through them. I was so much challenged and encouraged by other people who have made it against all odds.”

Having experienced this process in a directed manner and in a safe dialogical space, students are able to move from their own personal understanding to a position in their professional lives where they are able to work effectively and in partnership with others. A reflexive professional approach views others as experts in their own lives but in so doing acknowledges the complexities of this and understands that being your own expert has its own responsibility. Working in partnership entails acknowledging that person's context and background, that person's story and also facilitates space for a dialogue that supports informed decision-making. Once the student understands the reflexive process and its components in terms of their own lives; this can be used as an instrument for working with social issues and clients. This means 
showing an understanding that the same components are present in the life of the client and all need to be responded to in a holistic manner. For example, working with a mother of an undernourished child would require a stance that understands the context and poverty perspective in situations where there is a lack of access to food and resources rather than taking a blaming or expert stance.

"Having to listen to some people's sensitive stories has taught me to be sensitive and very attentive when dealing with people.”

Once these shifts have been made, it is no longer possible to go back, you see differently. We may well need reminding, and it is important for reflexive practice to become a part of who we are. However, it is hoped that after such an intensive reflexive process, students would then take a different view within their professional lives, one that involves looking at the bigger picture, prioritising the relevance of context and acknowledging the value of connecting to lived experience. We need to know that each person has a story and that each story is important and relevant.

\section{REFERENCES}

Bandura, A. 2001. Social cognitive theory: An agentic perspective. Annual Review Psychology 52: 16.

Biesta, G. and M. Tedder. 2007. Agency and learning in the lifecourse: Towards an ecological perspective, Studies in the Education of Adults 39(2): 132-149.

Bohm, D. 1996. On dialogue, ed. Lee Nichol. London: Routledge.

Cunliffe, A. 2008. Orientations to wocial constructionism: Relationally responsive social constructionism and its implications for knowledge and learning. Management Learning 39(2): 123-139.

Dhunpath, R. 2000. Life history methodology: “Narradigm” regained. Qualitative Studies in Education 13(5): 543-551.

Door, V. M. 2014. Critcal pedagogy and reflexivity: The issue of ethical consistency. International Jounal of Critical Pedagogy 5(2): 88-99.

Fook, J., S. White and F. Gardner. 2006. Critical reflection: A review of contemporary literature and understandings. In Critical reflections in health and social care, ed. S. White, J. Fook and F. Gardner, 3-20. Maidenhead: Open University Press.

Frank, A.W. 2010. Letting stories breath: A socio-narratology. Chicago: The University of Chicago Press.

Gergen, K. J. 1996. Social psychology as social construction: The emerging vision. For The message of social psychology: Perspectives on mind in society, ed. C. McGarty and A. Haslam. Oxford: Blackwell.

Gergen, K. J. 1999. An invitation to social construction. London: Sage Publication.

Gergen, K. J. 2009. Relational being: Beyond self and community. Oxford University Press.

Gilbert, A. and Y. Sliep. 2009. Reflexivity in the practice of social action: From self-to inter-relational reflexivity. South African Journal of Psychology 39(4): 468-479. 
Holstein, J. A. and J. F. Gubrium. 2011. The constructionist analytics of interpretive practice. In The Sage handbook of qualitative research, ed. N. K. Denzin and Y. S. Lincoln. Los Angeles: Sage Publications,

Mangadu, T. 2014. Empowering health promotion students on the Texas-Mexico border through digital storytelling: Implications for public health in vulnerable communities. TPHA Journal 66(3).

Morgan, S. and R. F. Dennehy. 2004. Using stories to reframe the social construction of reality: A trio of activities. Journal of Management Education 28(3): 372-389.

Naidu, T. and Y. Sliep. 2011. Contextual reflexivity: Towards contextually relevant research with South African HIV/AIDS home-based care volunteers. International Journal of Qualitative Methods 10(4): 431-443.

Rule, P. 2004. Dialogic spaces: Adult education projects and social engagements. International Journal of Lifelong Education 23(4): 319-334.

Sakamoto, I. and R. O. Pitner. 2005. Use of critical consciousness in anti-oppressive social work practice: Disentangling power dynamics at personal and structural levels. British Journal of Social Work 35: 435-452.

Scott, J. W. 1992. Experience. In Feminists theorize the political, ed. J. Butler and J. W. Scott. New York: Routledge, Chapman and Hall, Inc.

Skovdal, M. and T. Abebe. 2012. Reflexivity and dialogue: Methodological and socio-ethical dilemmas in research with HIV-affected children in East Africa. Ethics, Policy and Environment 15(1): $77-$ 96.

Sliep, Y. 2003. Building partnerships in responding to vulnerable children: A rural African community context. International Journal of Narrative Therapy and Community Work 2: 56-66.

Sliep, Y. 2010. Teaching for transformation: The use of narrative metaphor to develop reflexive professionals. Acta Academica: Teaching of psychology in South Africa: Supplementum 2: 109132.

Sliep, Y. 2016. Poetry as dialogue: Navigating the storms. In Stories that make a difference: Exploring the collective, social and political potential of narratives in adult education research, ed. L. Formenti and L. West, 172-180. Italy: Pensa, MultiMedia.

Sliep, Y. and A. Gilbert. 2006. Promoting inter-relational reflexivity with psychosocial workers in community work: A case study from Burundi. Journal of Psychology in Africa 2: 293-302.

Sliep, Y. and E. Kotze. 2007. Weaving a learning community by the telling, deconstructing and retelling of life stories. In Shaping the story: A guide to facilitating narrative career counselling, ed. Kobus Maree, 138-150. Rotterdam: Sense Publishers.

Sliep, Y and L. Norton. 2016. Trees, poems and drama to create reflexive spaces for peace building in schools. In Peace education for violence prevention in fragile African societies: What's going to make a difference?, ed. Sylvester Mpahosa and Alphonse Keasley, 243-274. Africa Institute of South Africa, Pretoria.

Sliep, Y., K. Weingarten and A. Gilbert. 2004. Narrative theatre as an interactive community approach to mobilizing collective action in Northern Uganda. Families, Systems and Health 22(3): 306320.

Suarez-Ortega, M. 2013. Performance, reflexivity, and learning through biographical narrative research. Qualitative Inquiry 19(3): 189-200.

Tamboukou, M., M. Andrews and C. Squire. 2013. Introduction: What is narrative research. In Doing Narrative Research, ed. M. Andrews, C. Squire and M. Tamboukou. $2^{\text {nd }}$ Edition. London: Sage Publications.

Waghid, Y. 2002. Knowledge production and higher education transformation in South Africa: Towards reflexivity in university teaching, research and community service. Higher Education 43(4): 457-488. 